\title{
Avaliação do perfil energético de caprinos criados extensivamente no semiárido
}

Rodolfo G Vale ${ }^{[a]}$, Jucélio da Silva Gameleira ${ }^{[b]}$, Aluisio de Souza Neto ${ }^{[b]}$, Estela Ivone Borges Lemos ${ }^{[b]}$, Francisco Jocelho Alexandre de Souza ${ }^{[b]}$, Isabella de Oliveira Barros ${ }^{[c]}$, Jerson Marques Cavalcante ${ }^{[b]}$, Francisco Fernandes Feitoza Neto ${ }^{[b]}$, Rejane Santos Sousa ${ }^{[d]}$, Raimundo Alves Barrêto Júnior ${ }^{[b]]^{*}}$

\footnotetext{
[a] Centro Universitário Luterano de Ji-Paraná (CEULJI), Ji-Paraná, RO, Brasil

[b] Departamento de Ciência Animal, Universidade Federal Rural do Semi-Árido (UFERSA), Mossoró, RN, Brasil

[c] Departamento de Ciências Veterinárias, Centro de Ciências Agrárias, Universidade Federal da Paraíba (UFPB), Areia, PB, Brasil

${ }^{[\mathrm{d}]}$ Faculdade de Medicina Veterinária e Zooctenia, Universidade de São Paulo (USP), São Paulo, SP, Brasil
}

*Autor correspondente

e-mail: barreto@ufersa.edu.br

\section{Resumo}

A criação de caprinos concentra mais de 90\% do rebanho nacional na região Nordeste, sendo uma importante fonte de renda e alimentação principalmente para os produtores rurais. Esta atividade está limitada nessa região pela sazonalidade do período chuvoso curto e de baixa intensidade pluviométrica. 0 período seco prolongado acaba por diminuir o aporte forrageiro ao longo do ano, favorecendo o aparecimento de doenças no rebanho. Esse fato releva a necessidade de estudos que avaliem o perfil energético de caprinos criados extensivamente no semiárido nordestino. Foram utilizados 20 caprinos mestiços, machos, castrados, entre 6 e 8 meses de idade, pesando aproximadamente $25 \mathrm{~kg}$, hígidos, mantidos em duas propriedades na região de Mossoró/RN. Durante 12 meses esses animais foram acompanhados, com o sangue coletado mensalmente para avaliação do perfil energético, através de beta-hidroxibutirato $(0-0,7 \mathrm{mmol} / \mathrm{L})$, ácidos graxos não esterificados $(<0,4 \mathrm{mmol} / \mathrm{L})$ e colesterol $(52-76 \mathrm{mg} / \mathrm{dL})$. 0 colesterol apresentou valores inferiores aos de referência para espécie 47,20 mg/dL no mês de março, e valores mínimos nos meses de abril e dezembro, 52,42 e 52,47 mg/dL, respectivamente. Já os valores de BHB e AGNE se mantiveram dentro da normalidade durante todo o experimento. Vale ressaltar que principalmente em abril (mês de maior índice pluviométrico) pode-se notar valores menores de colesterol, junto a valores maiores de BHB (0,268 mmol/L) e AGNE $(0,468$ mmol/L). Esses dados reforçam a mobilização de lipídios para suprir a necessidade energética desses animais, influenciada pela umidade das pastagens, diminuição do pastejo dos animais e menor oferta de alimento arbustivo-arbóreo (preferência dos caprinos), devido ao início do período chuvoso. Dessa forma podemos sugerir a suplementação energética de caprinos criados no semiárido nordestino, principalmente no período das chuvas, período de menor pastejo dos caprinos e de pastagem degradadas. 